\title{
Role of acid efflux during growth promotion of primary leaves of Phaseolus vulgaris L. by hormones and light
}

\author{
Thomas G. Brock ${ }^{1 *}$ and Robert E. Cleland ${ }^{2}$ \\ ${ }^{1}$ Department of Biology, University of Michigan, Ann Arbor, MI 48109, and \\ 2 Department of Botany, University of Washington, Seattle, WA 98195, USA
}

\begin{abstract}
The white-light-(WL) induced enlargement of dicotyledonous leaf cells is known to occur via an acid-growth mechanism; i.e., WL causes leaf cells to excrete protons which lead to an increase in wall extensibility and thus cell enlargement. Gibberellic acid $\left(\mathrm{GA}_{3}\right)$ and $\mathrm{N}^{6}$-benzyladenine (BA) also induce leaf cell enlargement. To see if they also act via acid-induced cell wall loosening, a comparison has been made of WL-, $\mathrm{GA}_{3}$ - and BAinduced growth of strips, taken from primary leaves of bean (Phaseolus vulgaris L.) plants raised in continuous red light for $10 \mathrm{~d}$. White light, $\mathrm{GA}_{3}$ and BA all increased wall extensibility as measured by the Instron technique, and this change preceded the increase in growth rate. However, whereas WL induced significant proton excretion, neither $\mathrm{GA}_{3}$ nor BA caused any acidification of the apoplast. Furthermore, neutral buffers, which effectively inhibited the growth induced by WL, were without effect on growth promoted by either $\mathrm{GA}_{3}$ or BA. These results indicate that while WL, GA $\mathrm{GA}_{3}$ and $\mathrm{BA}$ all initiate growth in bean leaves by altering cell-wall properties, $\mathrm{GA}_{3}$ and $\mathrm{BA}$ do so through some wall loosening mechanism other than wall acidification. Neither gibberellin nor cytokinin is likely to play a major role in light-induced cell enlargement of dicotyledonous leaves.
\end{abstract}

Key words: Cell wall extensibility - Cell wall acidification - Cytokinin and leaf growth - Gibberellin and leaf growth - Light and leaf growth - Phaseolus (leaf growth).

\footnotetext{
* To whom correspondence should be addressed

Abbreviations: $\quad \mathrm{BA}=\mathrm{N}^{6}$-benzyladenine; $\quad \mathrm{FC}=$ fusicoccin; $\mathrm{GA}_{3}=$ gibberellic acid; $\mathrm{RL}=$ red light; $\mathrm{SK}$ medium $=10 \mathrm{mM}$ sucrose $+10 \mathrm{mM} \mathrm{KCl}$; WL = white light
}

\section{Introduction}

White light (WL) promotes the growth of bean leaves and this stimulation of rapid cell expansion occurs via an acid-induced increase in wall extensibility (Van Volkenburgh and Cleland 1979, 1980). The growth of etiolated bean leaves can also be promoted by gibberellins and cytokinins (Miller 1956; Scott and Liverman 1956; Humphries and Wheeler 1960; Powell and Griffith 1960). These hormones also induce cell enlargement in the primary leaves of red-light-grown bean plants (Göring et al. 1984). Furthermore, exposure to light has been reported to result in rapid, transient increases in cytokinins (Hewett and Wareing 1973; Thompson et al. 1975) and gibberellin-like substances (Reid et al. 1968; Beevers et al. 1970) in a variety of leaves from etiolated or dark-grown plants. These findings indicate that gibberellins or cytokinins might mediate the WL-induced promotion of growth of bean leaves. If this is the case, then gibberellins or cytokinins should also cause an acid-induced increase in wall extensibility. To date, there has been little information regarding the effects of hormones on the wall properties of dicotyledonous leaves during growth promotion (see Discussion).

In the present paper we examine the action of gibberellic acid $\left(\mathrm{GA}_{3}\right)$ and $\mathrm{N}^{6}$-benzyladenine (BA) during growth promotion in bean leaves with respect to the criteria for acid-growth. We have used primary leaves from 10-d old plants raised in continuous red light (RL) because leaf growth following day 10 under this regime occurs without the complication of cell division (Van Volkenburgh and Cleland 1979). Also, since our primary interest is the initiation of the rapid growth response, we have determined the timing of the initiation of ra- 
pid growth following light and hormone treatment, and monitored wall extensibility and acidification responses in the relevant time frame.

\section{Material and methods}

Material. Seedlings of Phaseolus vulgaris L. cv. Contender (Olds Seed Co., Madison, Wis., USA) were raised for $10 \mathrm{~d}$ under continuous dim RL, as described in Van Volkenburgh and Cleland (1979). Leaf strips, $5.10 \mathrm{~mm}^{2}$, were excised parallel to the midrib from primary leaves and pretreated for $2 \mathrm{~h}$ by floating adaxial side down on $10 \mathrm{mM}$ sucrose plus $10 \mathrm{mM} \mathrm{KCl}$ ("SK medium"), titrated to $\mathrm{pH} 6.6 \pm 0.1$ with $10 \mathrm{mM}$ Tris (2amino-2-(hydroxymethyl)-1,3-propanediol), unless otherwise noted.

All chemicals were from Sigma Chemical Co., St. Louis, Mo., except fusicoccin (FC), which was the generous gift of Dr. E. Marré, University of Milan, Italy. Hormones were applied at a final concentration of $10 \mu \mathrm{M}$ since preliminary tests indicated that this concentration gave the optimum growth response for both hormones. Fusicoccin was applied at $1 \mu \mathrm{M}$.

Evaluation of growth. Leaf strips were prepared as described, pretreated for $2 \mathrm{~h}$ on SK medium under RL, measured with a dissecting scope fitted with a measuring ocular, then transferred to fresh SK medium with or without $\mathrm{GA}_{3}$ or $\mathrm{BA}$ (each at $10 \mu \mathrm{M})$. Samples were incubated atop a shaker table $(25 \mathrm{rpm})$ under continuous RL or WL. After $24 \mathrm{~h}$ of treatment, samples were again measured using the dissecting scope.

In order to detail the timing of the initiation of the growth response to $\mathrm{WL}, \mathrm{GA}_{3}$ and $\mathrm{BA}$ the growth of individual strips was measured continuously using a rotary variable displacement transducer (model R30D; Schaevitz Engineering, Pennsauken, N.J., USA) on line with a strip-chart recorder (Brock 1985). In dim RL, a single leaf strip, $5.14 \mathrm{~mm}^{2}$, was excised, placed in a horizontal position, and clamped at one end to a clip fixed in place in a plastic Petri dish. A second clip, fastened to the transducer and free to move, was attached to the other end of the strip, leaving $10 \mathrm{~mm}$ of leaf tissue between clips. A $1.0 \mathrm{~g}$ weight, acting through a pulley, was attached to the opposite side of the mobile clip to add a minimal tension to the system and give a smoother growth measurement. The SK medium was added by a measuring pipet to the dish until the solution came in contact with the underside of the strip, and the dish was covered. Absolute growth rate $\left(\mathrm{mm} \cdot \mathrm{h}^{-1}\right)$ of 10 -mm strips (initial strip length between clips) was calculated as a running average from recorder printouts using 10-min intervals. Growth rate obtained by this procedure under RL was approximately constant within $1 \mathrm{~h}$ and remained so over $24 \mathrm{~h}$ (data not shown). Hormones were added, using a $100 \mu \mathrm{M}$ stock solution, to the measured volume of added SK medium, to give a final hormonal concentration of $10 \mu \mathrm{M}$. White light was applied using a microscope lamp filtered through $10 \mathrm{~cm}$ of water, with a fluence rate of $250 \mu \mathrm{mol} \cdot \mathrm{m}^{-2} \cdot \mathrm{s}^{-1}$ at the tissue surface.

Measurements of plastic extensibility. Plastic extensibility was evaluated using an Instron TM-S extensometer, as described in Cleland $(1967,1984)$. This involved extending methanolboiled, water-rehydrated tissue twice to an applied load of $20 \mathrm{~g}$. Plastic extensibility was calculated as the difference of the slopes of the two load-extension curves (i.e., total extensibility minus elastic extensibility) and expressed as \% extension/20 g load.

Acidification tests. Two different methods for monitoring $\mathrm{pH}$ were employed. A solution method, or media acidification test, used a relatively large mass of tissue over a protracted treatment time and was useful for determining presence or absence of response. A surface method was also used to increase the sensitivity of measurement by decreasing solution volume and cell number, giving a more accurate picture of the magnitude and kinetics of the response.

In the solution method, leaf tips $(5 \mathrm{~mm})$ and bases were removed from 10-d-old leaves, under RL, and discarded. The remaining tissue from six leaves (approx $400 \mathrm{mg}$ total) was further cut into 3-mm strips, placed in $3 \mathrm{ml} \mathrm{SK}$ medium, $\mathrm{pH} 6.6$, in a covered Petri dish, and put on a rotary shaker at $25 \mathrm{rpm}$. After a 2-h pretreatment the dish was tilted to separate solution from tissue, the solution was drained, the tissue was blotted dry, and $3 \mathrm{ml}$ of test solution, titrated to $\mathrm{pH} 6.6 \pm 0.1$ with Tris, was added. The covered dish was then returned to the rotary shaker and the appropriate light or hormone treatment was begun. Measurements of the $\mathrm{pH}$ of the solution were taken with a flat-tipped combination electrode, allowing $30 \mathrm{~s}$ for equilibration.

In the surface method, one 10-d-old plant, under RL, was severed at the stem above the cotyledon and the base was placed in water. A small area of the adaxial surface of one leaf was gently abraded with a fine powder (grade M180; American Optical, Seattle), rinsed to remove the powder, and blotted dry. The leaf was placed on a square of parafilm over wet paper towelling in a Petri dish modified with an opening for the petiole. A single drop (approx $10 \mu \mathrm{l}$ ) of $1.0 \mathrm{mM} \mathrm{KCl}$ was placed on the abraded area and the dish was covered. A flat-tipped combination electrode was lowered through a hole in the dish cover until it contacted the drop of solution. Output from the pH meter was recorded continuously by strip-chart recorder. Additional solution was added or withdrawn by micropipet at the leaf-electrode interface, as necessary. White light was applied using a microscope lamp, as described above.

Effect of neutral buffers on growth. Leaf strips were pretreated with SK medium in RL for $2 \mathrm{~h}$, then vacuum-infiltrated with SK medium with or without hormones. These solutions were (1) titrated to pH 6.6 using $10 \mathrm{mM}$ Tris, (2) buffered at $\mathrm{pH} 6.6$ with $10 \mathrm{mM}$ Tris + Mes (Mes=2-(N-morpholino)ethanesulfonic acid), or (3) titrated to $\mathrm{pH} 6.6$ using $10 \mathrm{mM}$ Tris, with polyethylene glycol 6000 added to duplicate the osmotic potential of the $10 \mathrm{mM} \mathrm{Mes}+$ Tris solutions. Osmotic potentials of all solutions were measured by freezing-point-depression osmometer (model 3L; Advanced Instruments, Needham Heights, Mass., USA). Tissue infiltration was achieved by placing strips with the appropriate solution in a vacuum desiccator, with a vacuum generated by a faucet aspirator, for $1 \mathrm{~min}$. After infiltration, the strips were placed on $3 \mathrm{ml}$ test solution for $6 \mathrm{~h}$, and then measured.

Replication and statistical analysis. All experiments were repeated at least three times, with sample size typically ten per condition. Transducer figures and surface-pH figures are from individual tests and are representative of at least five independent tests per condition. The Student's t-test was used to evaluate statistical significance, using a $95 \%$ confidence level.

\section{Results}

Leaf strip growth. Upon being excised and floated on SK medium, leaf strips increased in length and width rapidly at first (data not shown). This apparently was the result of passive water uptake. By 
Table 1. The effect of white light, $\mathrm{GA}_{3}$, and $\mathrm{BA}$ on growth of bean leaf strips over $24 \mathrm{~h}$. Strips, $5.10 \mathrm{~mm}^{2}$, were excised from the primary leaves of 10 -d-old RL-grown plants and pretreated with SK medium in RL. After $2 \mathrm{~h}$, the strips were measured and transferred to fresh solutions of SK medium under $\mathrm{RL}$ or WL, or given SK medium plus $10 \mu \mathrm{M} \mathrm{GA}{ }_{3}$ or BA and left in RL. The lengths and widths of strips were again measured after $24 \mathrm{~h}$ of treatment. Results are presented as the percent change over $24 \mathrm{~h}$ from initial values

\begin{tabular}{lllr}
\hline & \multicolumn{2}{l}{ Change (\%) } & \\
\cline { 2 - 4 } & Length & Width & Area \\
\hline Control (RL) & 22 & 18 & 44 \\
WL & 52 & 45 & 120 \\
GA & 45 & 44 & 109 \\
BA & 39 & 34 & 86 \\
\hline
\end{tabular}

$2 \mathrm{~h}$ this expansion was reduced to a continuous rate of growth of approx $1 \% \cdot \mathrm{h}^{-1}$ in $\mathrm{RL}$ in the presence of SK medium. Over $24 \mathrm{~h}$, leaf strips increased $22 \%$ in length and $18 \%$ in width in RL (Table 1). Treatment with either WL or $\mathrm{GA}_{3}$ more than doubled the enlargement over the same period, generating a substantial increase in leaf strip area. Benzyladenine produced a somewhat smaller promotion of growth than either WL or $\mathrm{GA}_{3}$. In all cases, the percent change in width was comparable to the percent change in length. A qualitatively similar promotion of leaf growth could be produced in intact plants by applying SK medium with $\mathrm{BA}$ or $\mathrm{GA}_{3}$ directly to the leaf surfaces (data not shown) or by exposure to WL (Van Volkenburgh and Cleland 1979).

Early changes in growth rate. White light is known to induce rapid expansion in bean leaves after a lag of only $15 \mathrm{~min}$ (Van Volkenburgh and Cleland 1980), but the rapidity with which $\mathrm{GA}_{3}$ and BA enhance growth was not known. To obtain this information, leaf strips were mounted in a transducer apparatus with $10 \mathrm{~mm}$ of leaf tissue between clips and the growth of individual strips was monitored continuously before and after treatment with the two hormones or with WL. As noted above, leaf strips typically displayed a steady-state growth rate of approx $0.1 \mathrm{~mm} \cdot \mathrm{h}^{-1}$ in SK medium in RL. The addition of $\mathrm{GA}_{3}$ to the SK medium to give a final concentration of $10 \mu \mathrm{M} \mathrm{GA}_{3}$ initially resulted in a reduction of the growth of the strips (Fig. 1). By $50 \mathrm{~min}$ after addition of $\mathrm{GA}_{3}$, however, the growth rate exceeded the control rate. Replacing RL with WL also resulted in a strong initial inhibition of growth (Fig. 1). The growth rate returned to control levels by $50 \mathrm{~min}$ after $\mathrm{WL}$ treatment and rose to higher levels within $90 \mathrm{~min}$.

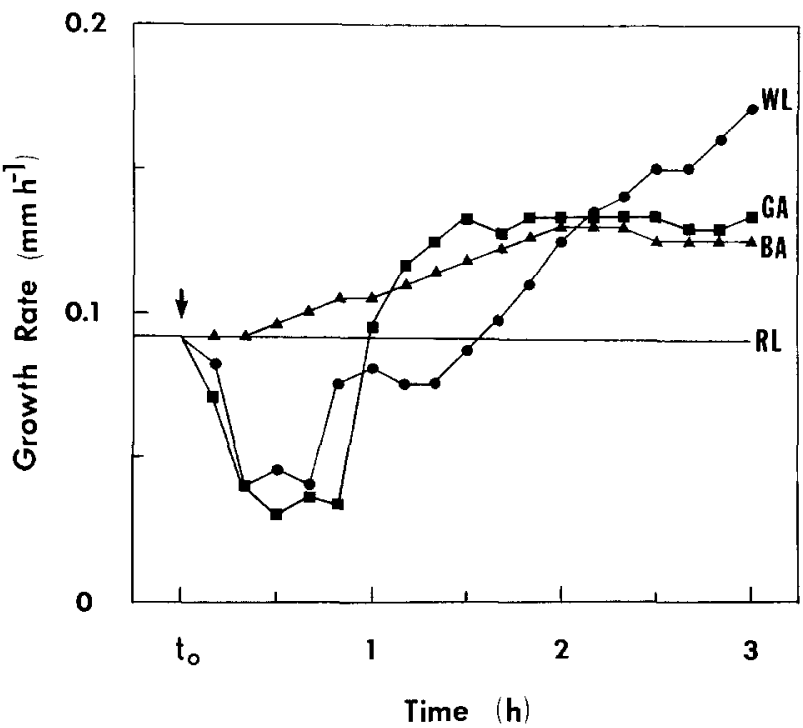

Fig. 1. Rapid changes in growth rate in response to $W L, G_{3}$ or BA of bean leaf strips as measured by displacement transducer. Hormones $(10 \mu \mathrm{M})$ or WL $\left(250 \mu \mathrm{mol} \cdot \mathrm{m}^{-2} \cdot \mathrm{s}^{-1}\right)$ were applied (arrow) after a steady-state growth rate was achieved during a 2-h pretreatment in RL with SK medium. Values represent running average growth-rate values measured over the previous 10 -min interval

The addition of BA (10 $\mu \mathrm{M}$ final concentration) to the SK medium in RL resulted in an enhancement of growth after a lag of 30-40 min. An initial depression of growth rate after BA application was only occasionally observed. Thus, WL, GA 3 and BA all increase the growth rate of bean leaf strips after a lag of up to $1 \mathrm{~h}$, and growth promotion persisted for up to $24 \mathrm{~h}$.

Changes in plastic extensibility of cell walls. No statistically significant change in plastic extensibility was found in isolated leaf strips treated with continuous RL and SK medium for $3 \mathrm{~h}$ (Fig. 2). Treatment with BA, GA 3 or WL produced statistically significant increases in plastic extensibility in $30 \mathrm{~min}$ and this continued through the first hour after treatment application. Between 60 and $150 \mathrm{~min}$, extensibility showed only small changes: a slight increase with WL and a slight decrease with $\mathrm{GA}_{3}$. With $\mathrm{BA}$, extensibility usually showed a second large increase after $150 \mathrm{~min}$.

Solution and leaf-surface acidification. When changes in solution $\mathrm{pH}$ were followed over $6 \mathrm{~h}$, WL induced a large acidification response from leaf strips, while RL did not (Fig. 3), as previously reported (Van Volkenburgh and Cleland 1980). Neither $\mathrm{GA}_{3}$ nor BA (each at $10 \mu \mathrm{M}$ ) decreased the solution $\mathrm{pH}$ over the same time interval. Fusicoccin $(\mathrm{FC} ; 1 \mu \mathrm{M})$, used as a control, was found 


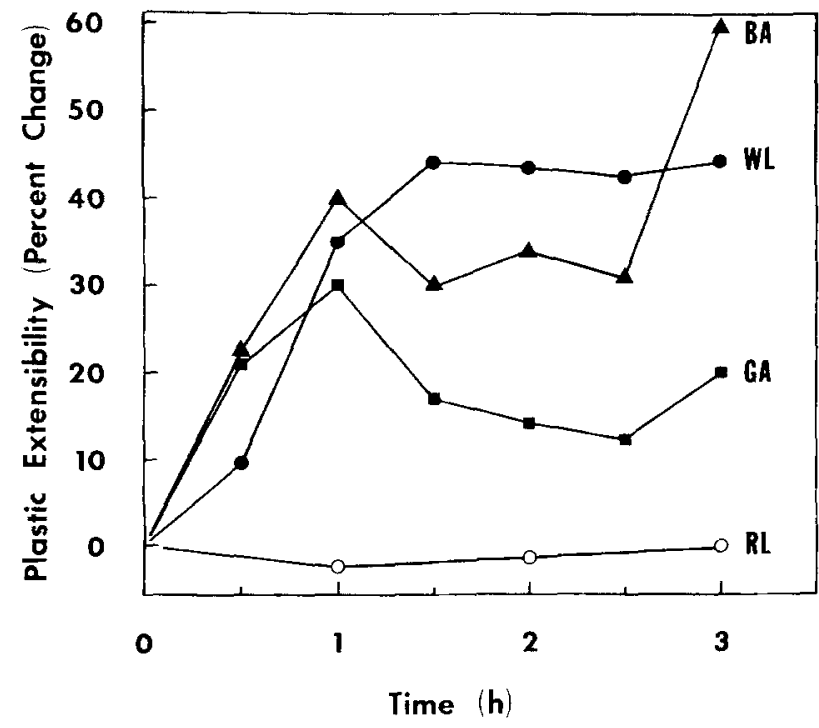

Fig. 2. Effects of WL, GA $\mathrm{G}_{3}$, and $B A$ on the plastic extensibility of bean leaf strips, incubated in SK medium. Plastic extensibility was measured by the Instron method. Values are presented as the percent change from the initial mean extensibility value of $46.2 \%$ extension $/ 20 \mathrm{~g}$ load. SE values were $10 \%$ or less of the mean

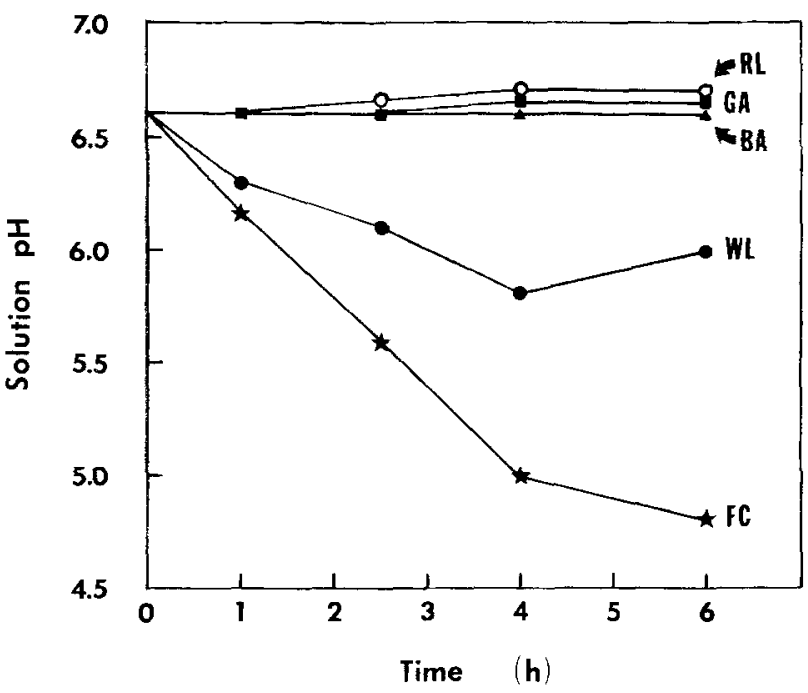

Fig. 3. Effects of WL, $\mathrm{GA}_{3}, \mathrm{BA}$ and fusicoccin $(\mathrm{FC})$ on the $\mathrm{pH}$ of the treatment solution. Leaf tissue was pretreated in SK medium ( $\mathrm{pH}=6.6$ ) for $2 \mathrm{~h}$. This solution was then replaced with SK medium $(\mathrm{pH}=6.6) \pm \mathrm{GA}_{3}(10 \mu \mathrm{M}), \mathrm{BA}(10 \mu \mathrm{M})$ or fusicoccin ( $\mathrm{FC} ; 1 \mu \mathrm{M})$ and placed in $\mathrm{RL}$ or $\mathrm{WL}$

to generate a large $\mathrm{pH}$ decrease, indicating that the solution method could effectively measure $\mathrm{pH}$ changes induced by applied agents.

A similar general pattern, on a contracted time scale, was observed when $\mathrm{pH}$ was monitored at the leaf surface. When a combination electrode was placed in contact with a drop of $\mathrm{KCl}$ on the abraded leaf surface, acidification was observed in

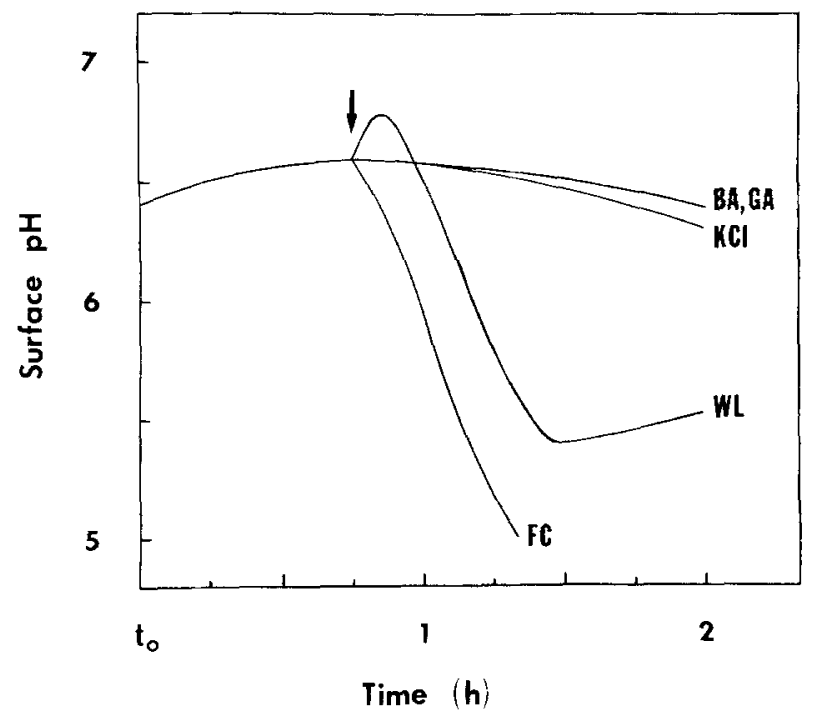

Fig. 4. Effects of $W L, G A_{3}, B A$ and $F C$ on the $p H$ at the epidermal surface of the bean leaf. The surface $\mathrm{pH}$ was measured continuously using a flat-tipped combination electrode placed in contact with $0.01 \mathrm{ml} 1 \mathrm{mM} \mathrm{KCl}$ at an abraded epidermal region. White light, hormones, or $\mathrm{FC}$, with $\mathrm{KCl}$, were applied after $45 \mathrm{~min}$ (arrow). Each line is from one leaf, one experiment, and is representative of at least five independent trials

response to WL, after an initial increase in $\mathrm{pH}$ (Fig. 4). Replacement of the drop of $\mathrm{KCl}$ at the leaf surface with $\mathrm{KCl}$ containing either $\mathrm{GA}_{3}$ or $B A$, in continuous RL, did not result in a significant acidification response. Application of FC plus $\mathrm{KCl}$, however, caused a rapid decrease in $\mathrm{pH}$, indicating that this technique was also capable of measuring $\mathrm{pH}$ changes induced by agents applied to the leaf surface.

The effect of neutral buffers on growth promotion. An indirect test for an acidification response and, more importantly, a direct test of the importance of an acidic apoplast to the promotion of growth, comes from the evaluation of the effect of neutral buffers on the growth response. If neutral buffers can inhibit the promotion of growth, then an acidic apoplast must be necessary for the response. Treatment of leaf strips with buffers inhibited the growth response induced by WL (Table 2), as shown earlier by Van Volkenburgh and Cleland (1980). This was not an osmotic effect since treatment of strips with an unbuffered solution, made iso-osmotic to the buffer using polyethylene glycol, did not inhibit WL-induced growth. On the other hand, there was no statistically significant difference between the growth response of leaf strips with or without the hormonal treatments, whether solutions were unbuffered, buffered, or unbuffered but isoosmotic to the buffered solution. 
Table 2. The effect of neutral buffers on growth promotion in bean leaf strips. Leaf strips were vacuum-infiltrated with a) SK medium titrated to pH 6.6 with Tris ("unbuffered"), b) SK medium buffered with $10 \mathrm{mM}$ Mes + Tris, $\mathrm{pH} 6.6$, or c) SK medium, made iso-osmotic to solution (b) using polyethylene glycol (PEG) 6000 and unbuffered but titrated to $\mathrm{pH} 6.6$ with Tris. The strips were subsequently treated with WL, GA or BA in an identical SK medium for $6 \mathrm{~h}$

\begin{tabular}{lccc}
\hline & \multicolumn{2}{l}{ Change in length (\%) } \\
\cline { 2 - 4 } & Unbuffered & Buffered & $\begin{array}{c}\text { Unbuffered } \\
\text { with PEG 6000 }\end{array}$ \\
\hline Control (RL) & 5.9 & 6.4 & 6.2 \\
WL & 9.7 & 5.4 & 9.6 \\
GA & 8.6 & 8.6 & 8.4 \\
BA & 10.8 & 9.2 & 10.5 \\
\hline
\end{tabular}

\section{Discussion}

The ability of WL, gibberellin and cytokinin to promote the growth of dicotyledonous leaves is well established (e.g. Van Volkenburgh and Cleland 1979; Humphries and Wheeler 1960; Miller 1956), and has also been observed here. The initial growth responses, and lags to growth promotion, have been investigated here for strips cut from primary leaves of bean. White light first caused a transitory inhibition of the growth rate, followed by a stimulation of the rate after $45-50 \mathrm{~min}$ (Fig. 1). Gibberellic acid also caused an inhibition of growth at first, followed by stimulation after $50 \mathrm{~min}$. Benzyladenine promoted growth after a lag of about $30 \mathrm{~min}$ with no initial inhibition. The lag period for $\mathrm{GA}_{3}$-induced leaf growth has apparently not been measured previously. The lags for $\mathrm{GA}_{3}$-induced growth of lettuce hypocotyls was less than $5 \mathrm{~min}$ (Moll and Jones 1981) and between 17 and $78 \mathrm{~min}$ for Avena internode sections, depending upon conditions (Adams and Ross 1983). Lags for promotion of leaf growth by cytokinins have varied from $1 \mathrm{~h}$ (Göring et al. 1984) for bean leaves to over $5 \mathrm{~h}$ for cucumber cotyledons (Ross and Rayle 1982). Thus the lag periods recorded here are not unexpected.

An increase in the growth rate requires an increase in either wall extensibility or in the effective turgor (the turgor in excess of the yield threshold; Lockhart 1965). Changes in growth rate in response to hormones or light have usually been ascribed to changes in wall extensibility (Cleland 1986). For example, increases in wall extensibility have been recorded during cytokinin-induced growth of Luffa cylindrica (Virk et al. 1985), radish and cucumber hypocotyls (Thomas et al. 1981) and $\mathrm{GA}_{3}$-induced growth of oat internodes (Adams et al. 1975), lettuce hypocotyls (Kamisaka et al.
1972) and pea epicotyls (Nakamura et al. 1975). A decrease in wall extensibility has been detected during blue light-induced inhibition of cucumber hypocotyl growth (Cosgrove and Green 1981).

White-light-induced growth of bean leaves has been shown to be a consequence of an increase in wall extensibility, not a change in the effective turgor (Van Volkenburgh and Cleland 1980, 1981). We have confirmed that WL increases wall extensibility in bean leaf cells, and have shown that the increase begins within $30 \mathrm{~min}$, i.e., prior to the onset of rapid growth. Furthermore, both $\mathrm{GA}_{3}$ and $\mathrm{BA}$ also enhanced wall extensibility prior to the onset of rapid growth (Fig. 2). This indicates that all three agents promote leaf enlargement by causing an increase in wall extensibility.

The initial inhibition of leaf growth in response to WL and $\mathrm{GA}_{3}$ may have resulted from either an initial decrease in wall extensibility or effective turgor. Such a biophysical change would have to precede the initial drop in growth rate, and so would have had to occur immediately upon treatment. Our earliest measurement of wall extensibility was at $30 \mathrm{~min}$ and we did not assess effective turgor. As a result, the biophysical basis for the initial drop in growth rate is presently unclear.

The WL-induced growth of bean leaves has been shown to be primarily caused by an acidgrowth mechanism (Van Volkenburgh and Cleland 1980). White light caused an acidification from the epidermal cells after a lag of only 10-15 min. This has been confirmed here (Fig. 4). Under the same conditions, FC caused an even more rapid acidification. However, neither $\mathrm{GA}_{3}$ nor BA caused any acidification (Fig. 3, 4). In addition, neutral buffers which inhibited WL-induced leaf growth (Van Volkenburgh and Cleland 1980) had no effect on $\mathrm{GA}_{3^{-}}$ or BA-induced leaf growth. We must conclude that both $\mathrm{GA}_{3}$ and $\mathrm{BA}$ induce wall loosening through mechanisms which do not involve or even require the acidification of the apoplastic solution.

A variety of hormone- and light-induced growth responses have been shown to occur via an acid-growth mechanism (for discussion, see Cleland 1986). In other cases, growth occurs by some other, acid-independent mechanism. These include auxin-induced growth of corn coleoptiles (Kutschera and Schopfer 1985), gibberellin-induced growth of lettuce hypocotyls (Stuart and Jones 1978), ethylene-induced growth of Ranunculus petioles (Craker et al. 1978) and cytokinin-induced expansion of cotyledons of cucumber (Ross and Rayle 1982) and watermelon (Fantelli et al. 1984). In each of these cases, as in the present $\mathrm{GA}_{3}$ - and $\mathrm{BA}$-induced growth of the bean leaf, an increase 
in wall extensibility was responsible for the growth promotion, but the mechanisms by which the wall loosening occurred were totally unknown. Wall loosening can only occur by the cleavage of loadbearing bonds in the wall, whether accompanied or not by the addition of new wall polysaccharides (Cleland 1971). If the load-bearing bonds are polysaccharide links, cleavage could occur in response to excretion into the walls of polysaccharide hydrolases. If the cleavage required the simultaneous addition of new wall polysaccharides, the rate of export of new wall precursors could limit wall loosening. Kutschera and Briggs (1987), for example, have suggested that the rate of incorporation of wall inositides limits wall loosening in pea epicotyls. If the load-bearing bonds are calcium crosslinks, solubilization of this calcium in response to excreted calcium chelators could lead to wall loosening. Moll and Jones (1981) have suggested that the acid-independent wall loosening that occurs during the $\mathrm{GA}_{3}$-induced growth of lettuce hypocotyls involves such a cleavage of calcium crosslinks. Convincing evidence for any of these theories is, however, lacking.

As pointed out in the Introduction, previous findings seemed to indicate that either a gibberellin or a cytokinin might mediate WL-induced leaf expansion. However, the data presented here do not support this hypothesis. White-light-induced wall loosening is acid-mediated and can be blocked by infiltration of neutral buffers into the cell walls. Wall loosening as induced by $\mathrm{GA}_{3}$ and $\mathrm{BA}$ does not involve the acidification of the cell wall and cannot be blocked by neutral buffers. Therefore, no major component of the WL-induced wall loosening in bean leaf cells can involve either of these hormones. If an accumulation of either gibberellin or cytokinin occurs in bean leaves in response to WL, it must either occur in cells other than the epidermal cells, which control the growth rate of dicotyledonous leaves (Van Volkenburgh and Cleland 1979), or it must result in hormone concentrations still too low to induce growth.

We thank Dr. R.B. Walker for his constructive criticisms during the execution of the work and Dr. E. Van Volkenburgh for her technical and theoretical help regarding the use of her bean leaf system. Thanks also to Carol M. Fast for her support and invaluable contributions and Peter Thomas for technical assistance. Supported by a grant from the National Science Foundation.

\section{References}

Adams, P.A., Ross, M.A. (1983) Interaction of indoleacetic acid and gibberellin in the short-term growth kinetics of oat stem segments. Plant Physiol. 73, 566-568
Adams, P.A., Montague, M.J., Tepfer, M., Rayle, D.L., Ikuma, H., Kaufman, P.B. (1975) Effect of gibberellic acid on the plasticity and elasticity of Avena stem segments. Plant Physiol. 56, 757-760

Beevers, L., Loveys, B., Pearson, J.A., Wareing, P.F. (1978) Phytochrome and hormonal control of expansion and greening of etiolated wheat leaves. Planta 90, 286-294

Brock, T.G. (1985) The role of hormones in leaf cell enlargement. Ph.D. thesis, University of Washington, Seattle

Cleland, R.E. (1967) Extensibility of isolated cell walls: measurement and changes during cell elongation. Planta 74, $197-209$

Cleland, R.E. (1971) Cell wall extension. Annu. Rev. Plant Physiol. 22, 197-222

Cleland, R.E. (1984) The Instron technique as a measure of immediate-past wall extensibility. Planta 160, 514-520

Cleland, R.E. (1986) The role of hormones in wall loosening and plant growth. Aust. J. Plant Physiol. 13, 93-103

Cosgrove, D.L., Green, P.B. (1981) Rapid suppression of growth by blue light. Biophysical mechanism of action. Plant Physiol. 68, 1447-1453

Craker, L.E., Cookson, C., Osborne, D. (1978) Control of proton extrusion and cell elongation by ethylene and auxin in the water plant Ranunculus sceleratus. Plant Sci. Lett. 12, 379-385

Fantelli, R., Longo, G.P., Rossi, G., Longo, C.P., Magnoni, L. (1984) Interaction between benzyladenine and fusicoccin on the development of excised watermelon cotyledons. II. Correlation between growth and proton extrusion. Plant Sci. Lett. 33, 277-284

Göring, H., Koshuchowa, S., Münnich, H., Dietrich, M. (1984) Stomatal opening and cell enlargement in response to light and phytohormone treatments in primary leaves of redlight-grown seedlings of Phaseolus vulgaris L. Plant Cell Physiol. 25, 683-690

Hewett, E.W., Wareing, P.F. (1973) Cytokinins in Populus $\times$ robusta (Schneid): Light effects on endogenous levels. Planta 114, 119-129

Humphries, E.C., Wheeler, A.W. (1960) The effects of kinetin, gibberellic acid, and light on expansion and cell division in leaf disks of dwarf bean (Phaseolus vulgaris). J. Exp. Bot. 11, 81-85

Kamisaka, S., Sano, H., Katsumi, M., Masuda, Y. (1972) Effects of cyclic AMP and GA on lettuce hypocotyl elongation and mechanical properties of its cell walls. Plant Cell Physiol. 13, 167-174

Kutschera, U., Briggs, W.R. (1987) Rapid auxin-induced stimulation of cell wall synthesis in pea internodes. Proc. Natl. Acad. Sci. USA 84, 2747-2751

Kutschera, U., Schopfer, P. (1985) Evidence against the acidgrowth theory of auxin action. Planta 163, 483-493

Lockhart, J.A. (1965) An analysis of irreversible plant cell elongation. J. Theor. Biol. 8, 264-275

Miller, C.O. (1956) Similarity of some kinetin and red light effects. Plant Physiol. 31, 318-319

Moll, C., Jones, R.L. (1981) Calcium and gibberellin-induced elongation of lettuce hypocotyl sections. Planta 152, 450456

Nakamura, T., Sekine, S., Arai, K., Takahashi, N. (1975) Effects of gibberellic acid and IAA on stress-relaxation properties of pea hook cell wall. Plant Cell Physiol. 16, 127-138

Powell, R.D., Griffith, M.M. (1960) Some anatomical effects of kinetin and red light on disks of bean leaves. Plant Physiol. 35, 273-275

Reid, D.M., Clements, J.B., Carr, D.J. (1968) Red light induction of gibberellin synthesis in leaves. Nature 217, 580-582

Ross, C.W., Rayle, D.L. (1982) Evaluation of $\mathrm{H}^{+}$-secretion 
relative to zeatin-induced growth of detached cucumber cotyledons. Plant Physiol. 70, 1470-1474

Scott, R.A., Liverman, J.L. (1957) Control of etiolated bean leaf-disk expansion by gibberellins and adenine. Science $\mathbf{1 2 6}$, 122-123

Stuart, D.A., Jones, R.L. (1978) The role of acidification in gibberellic acid- and fusicoccin-induced elongation of lettuce hypocotyl sections. Planta 142, 135-145

Thomas, J., Ross, C.W., Chastain, C.J., Koomanoff, N., Hendrix, J.E., Van Volkenburgh, E. (1981) Cytokinin-induced wall extensibility in excised cotyledons of radish and cucumber. Plant Physiol. 68, 107-110

Thompson, A.G., Horgan, R., Heald, J.K. (1975) A quantitative analysis of cytokinin using single-ion-current-monitoring. Planta 124, 140-151
Van Volkenburgh, E., Cleland, R.E. (1979) Separation of cell enlargement and division in bean leaves. Planta 146, 245247

Van Volkenburgh, E., Cleland, R.E. (1980) Proton excretion and cell expansion in bean leaves. Planta 148, 273-278

Van Volkenburgh, E., Cleland, R.E. (1981) Control of lightinduced bean leaf expansion: role of osmotic potential, wall yield stress, and hydraulic conductivity. Planta 153, 572-577

Virk, S.S., Singh, O.S., Batra, N., Kaur, R. (1985) Effect of cytokinin and moisture stress on cell expansion growth of etiolated cotyledons of sponge-gourd (Luffa cylindrica) Roxb. Ann. Bot. 55, 535-548

Received 9 May; accepted 1 November 1988 